\title{
Corrigendum: Modeling Bacillus cereus Growth and Cereulide Formation in Cereal-, Dairy-, Meat-, Vegetable-Based Food and Culture Medium
}

\author{
Mariem Ellouze ${ }^{\text {* }}$, Nathália Buss Da Silva ${ }^{2}$, Katia Rouzeau-Szynalski ${ }^{1}$, Laura Coisne ${ }^{1}$, \\ Frédérique Cantergiani ${ }^{1}$ and József Baranyi ${ }^{3}$
}

'Food Safety Microbiology, Food Safety Research Department, Institute of Food Safety and Analytical Sciences, Nestlé Research, Lausanne, Switzerland, ${ }^{2}$ Laboratory of Food Microbiology, Wageningen University \& Research, Wageningen, Netherlands, ${ }^{3}$ Institute of Nutrition, University of Debrecen, Debrecen, Hungary

Keywords: Bacillus cereus, growth, cereulide formation, predictive microbiology, food, culture medium

\section{A Corrigendum on}

Modeling Bacillus cereus Growth and Cereulide Formation in Cereal-, Dairy-, Meat-, Vegetable-Based Food and Culture Medium

by Ellouze, M., Buss Da Silva, N., Rouzeau-Szynalski, K., Coisne, L., Cantergiani, F., and Baranyi, J. (2021). Front. Microbiol. 12:639546. doi: 10.3389/fmicb.2021.639546

In the original article, there was an error. Equations 2 and 5 had a mistake in their denominator. A correction has been made to Materials and Methods, Bacillus cereus Growth, Growth

\section{OPEN ACCESS}

Edited and reviewed by: Giovanna Suzzi,

University of Teramo, Italy

*Correspondence: Mariem Ellouze mariem.ellouze@rdls.nestle.com

Specialty section: This article was submitted to

Food Microbiology, a section of the journal

Frontiers in Microbiology

Received: 09 August 2021 Accepted: 18 August 2021 Published: 22 September 2021

Citation:

Ellouze M, Buss Da Silva N Rouzeau-Szynalski K, Coisne L, Cantergiani F and Baranyi J (2021)

Corrigendum: Modeling Bacillus cereus Growth and Cereulide Formation in Cereal-, Dairy-, Meat-, Vegetable-Based Food and Culture Medium. Front. Microbiol. 12:755736.

doi: 10.3389/fmicb.2021.755736
Monitoring and Modeling section to change Equation 2 to the following expression:

$$
\begin{array}{r}
\gamma(T)=\frac{\left(T-T_{\max }\right)\left(T-T_{\min }\right)^{2}}{\left(T_{o p t}-T_{\min }\right)\left(\left(T_{o p t}-T_{\min }\right)\left(T-T_{o p t}\right)\right.} \\
\left.-\left(T_{o p t}-T_{\max }\right)\left(T_{o p t}+T_{\min }-2 T\right)\right)
\end{array}
$$

A correction has been made to Materials and Methods, Cereulide Modeling, Secondary and Tertiary Modeling section to change Equation 5 to the following expression:

$$
\begin{array}{r}
\gamma_{c e r}(T)=\frac{\left(T-T_{\max . c e r}\right)\left(T-T_{\min . c e r}\right)^{2}}{\left(T_{\text {opt.cer }}-T_{\min . c e r}\right)\left(\left(T_{\text {opt.cer }}-T_{\min . c e r}\right)\left(T-T_{\text {opt.cer }}\right)\right.} \\
\left.-\left(T_{\text {opt.cer }}-T_{\max . c e r}\right)\left(T_{\text {opt.cer }}+T_{\min . c e r}-2 T\right)\right)
\end{array}
$$

The authors apologize for this error and state that this does not change the scientific conclusions of the article in any way. The original article has been updated.

Publisher's Note: All claims expressed in this article are solely those of the authors and do not necessarily represent those of their affiliated organizations, or those of the publisher, the editors and the reviewers. Any product that may be evaluated in this article, or claim that may be made by its manufacturer, is not guaranteed or endorsed by the publisher.

Copyright () 2021 Ellouze, Buss Da Silva, Rouzeau-Szynalski, Coisne, Cantergiani and Baranyi. This is an open-access article distributed under the terms of the Creative Commons Attribution License (CC BY). The use, distribution or reproduction in other forums is permitted, provided the original author(s) and the copyright owner $(s)$ are credited and that the original publication in this journal is cited, in accordance with accepted academic practice. No use, distribution or reproduction is permitted which does not comply with these terms. 